\title{
Effect of wingtip morphing on the roll mode of a flexible aircraft
}

\author{
Gaétan Dussart*, Sezsy Yusuf ${ }^{\dagger}$ and Mudassir Lone ${ }^{\ddagger}$ \\ Cranfield University, Dynamic Simulation and Control Group \\ Cranfield, Bedfordshire, United Kingdom, MK43 OAL
}

\begin{abstract}
It is well known that increasing wing span leads to improved aerodynamic performances. To comply with airport infrastructure limits, ground folding wingtips are implemented as a solution for wing span extension. To further justify the mechanism's weight penalty the concept of in-flight folding is investigated here. A time domain aeroservoelastic simulation framework is used to asses its impact on lateral flight dynamics. An established system identification method, was used to derive key lateral aerodynamic derivatives and investigate the aircraft's roll handling qualities. A range of wingtip deflections and various flight conditions were used to generate a sufficiently large database of coefficients to assess the effect of wingtip morphing as a function of airframe flexibility and flight conditions. Results show that overall, small changes in lateral aerodynamic derivatives are introduced with wingtip morphing. Different trends in aerodynamic derivatives were identified as a function of flight condition and wingtip deflection, leading to the derivation of prediction models to replace the aerodynamic derivatives database.
\end{abstract}

\section{Introduction}

As a response to the ever growing emissions and carbon footprint of the aerospace industry, aircraft manufacturers and regulation agencies have agreed on a specific set of objectives for both short and long term future developments. ${ }^{1,2}$ These targets will require major changes to aircraft performance and current industrial practices. Engineers and researchers have continuously improved design methods to reach better performances of the now conventional tube and wing aircraft. But despite many years of experience and significant investments to develop more efficient designs, overall aerodynamic performance and efficiency have plateaued. Therefore, major aircraft manufacturers are considering disruptive aircraft designs, with significant changes to aerodynamic performance and layout of the aircraft. These designs are predicted to significantly help in reaching performance, environmental and efficiency goals ${ }^{1,2}$ and henceforth supersede the conventional layout.

An example of disruptive changes to conventional aerodynamic aircraft properties is the implementation of High Aspect Ratio Wings (HARW). The objective is to gradually replace the short range aircraft fleet with more fuel efficient models of similar size and operating classes. With demonstrated performance benefits in terms of lift to drag ratios, these concepts are serious candidates for short term applications as they could be manufactured and operated using similar infrastructures. Furthermore, most of the fuselage components could be kept identical to current comparable models. However, in order to benefit from improved aerodynamic performances, a HARW aircraft will have a wingspan that would exceed most airport ground operation limits. Similarly to what was historically implemented on naval based aircraft, where storage space is a key operational characteristic, dihedral morphing is considered as a mean to reduce aircraft wingspan during ground operations. This type of morphing can be found as early as the 1940's with the F4U Corsair but is still used today on naval based aircraft such as the Lockheed Martin F-35C (carrier variant) (Fig.1a). It has also emerged recently on larger civil aircraft designs such as the Boeing 777-X and the Boeing SUGAR concept (Fig.1b). Fitted with a wingtip dihedral morphing device, the HARW concepts

*PhD candidate, Dynamic Simulation and Control Group, g.x.dussart@cranfield.ac.uk

${ }^{\dagger}$ PhD candidate, Dynamic Simulation and Control Group, sezsy.yusuf@cranfield.ac.uk

‡Lecturer, Dynamic Simulation and Control Group, m.m.lone@cranfield.ac.uk

Published by AIAA. This is the Author Accepted Manuscript issued with: Creative Commons Attribution Non-Commercial License (CC:BY:NC 4.0). The final published version (version of record) is available online at DOI:10.2514/6.2018-1683. Please refer to any applicable publisher terms of use. 
would qualify in comparable categories and therefore, be operated within the same infrastructures as their predecessors, avoiding additional operational costs to airports and airlines. On the other hand, this morphing device brings additional costs in design, maintenance, operational complexity and aircraft flight efficiency.

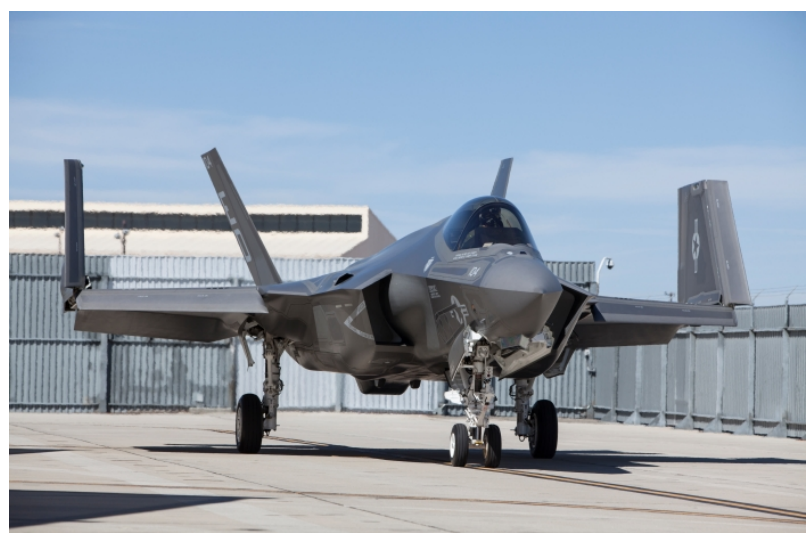

(a) Lockheed Martin F-35C Carrier Variant ${ }^{3}$

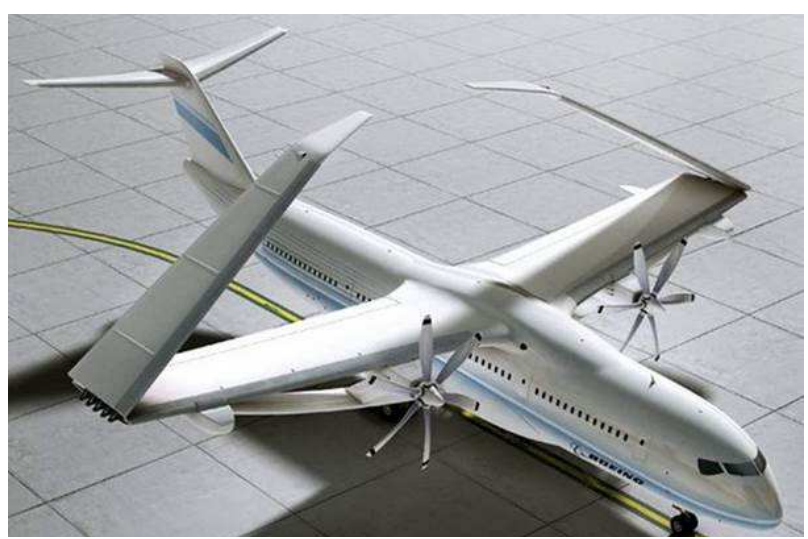

(b) Boeing SUGAR Concept ${ }^{4}$

Figure 1: Example of historical and concept aircraft equipped with ground dihedral morphing

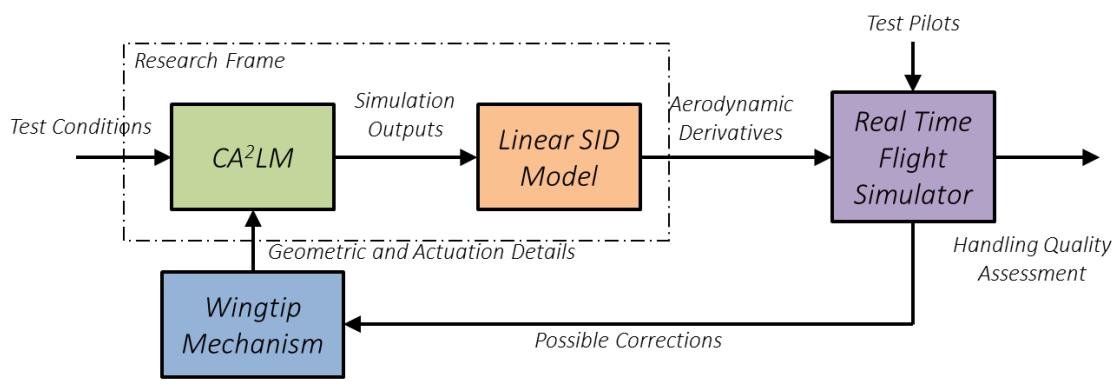

Figure 2: Research frame within the folding wingtip research project at Cranfield University

From a flight efficiency point of view, another problem arises. Using the classic Breguet range equation, it can be shown that carrying the morphing device and related additional weight during the entire flight will inherently reduce aircraft performance, ${ }^{5}$ jeopardising initial objectives. Hence, it would be beneficial to investigate and identify possible benefits of in-flight morphing using the wingtip folding device, such as loads alleviation or flight envelope extension. The implementation of the device would then be justified for both flight and ground operations but would require a more complicated certification process.

Any type of morphing, whether for loads alleviation or manoeuvring will surely lead to changes in aircraft flight dynamics. The response to pilot inputs or external disturbances compared to the baseline wing shape will change. The amplitude of the shift in flight dynamic properties relative to the baseline shape must therefore be quantified. The work discussed in this paper aims to provide preliminary insights on flight dynamic effects of dihedral wingtip morphing on a large generic civil aircraft.

More specifically, the impact of dihedral morphing on key lateral aerodynamic derivatives is investigated through the use of predictive simulations. The Cranfield Accelerated Aeroplane Loads Model (CA $\left.{ }^{2} \mathrm{LM}\right)$, a non-linear 6 Degrees of Freedom aircraft flight simulation environment, is used to provide flight dynamic results of the morphing aircraft in various morphing and flight conditions, after having developed and included a morphing device within the aircraft model. A systems identification method, described in this paper, is used to quantify the key lateral aerodynamic derivatives of interest at different flight conditions and morphing settings. A robust database is therefore derived for implementation on a real time flight simulator. Additionally, morphing correction models are developed so as to derive simple models to account for morphing wingtip devices to avoid reliance on large databases. This approach is similar to current practices used to model flaps or undercarriages,${ }^{6}$ where a correction factor or increment is added to the 
clean wing aerodynamic properties. The study is restrained to a single aircraft configuration and morphing device strategy. Baseline aircraft characteristics are also compared against data from Heffley \& Jewell. ${ }^{7}$ An illustration of the entire process, as well as the restricted scope of this particular research paper, is given in Fig.2.

The characteristics of the folding wingtip device is described in Section II, followed by simulation setup in Section III. In Section III, an outline of the manoeuvre conducted as well as the flight conditions being simulated are presented. Furthermore, the system identification process that quantifies aerodynamic derivatives are discussed in Section IV. The paper ends by listing the key findings and conclusions.

\section{Folding wingtip device characteristics}

The development and selection of the folding wingtip device is outside the scope of this research item, but the device must satisfy the following design requirements :

1. Significantly reduce aircraft wingspan during ground operations.

2. Provide aerodynamic loads alleviation capability, both through controlled and released -or failed- actuation.

3. Rely on systems with sufficient short term technological readiness level expectations.

Given these requirements, a hybrid dihedral morphing strategy is adopted. Aerodynamic loads alleviation can be achieved by reducing angle of attack or local twist of the aerofoil. By adding a flare angle to the dihedral rotation axis so as to be non-parallel to the flow, dihedral morphing leads to an effective twist modification. ${ }^{8}{ }^{8}$ Fig. 3b illustrates this flared mechanism where the hinge line is rotated around the vertical axis by a non-zero flare angle $\tilde{\psi}_{\text {hinge }}$. Dihedral rotation leads to an effective twist angle modification, given by :

$$
\Delta \theta=\tan ^{-1}\left(\tan \left(\Lambda^{\text {hinge }}\right) \times \sin \left(\Gamma^{w t}\right)\right)
$$

where $\Delta \theta$ is the change in local twist angle due to the hinge $\Gamma^{w t}$ dihedral position and mechanism hinge flare $\Lambda^{\text {hinge }}$. A hinge line pointing outward on the leading edge effectively leads to a decrease in local angle of attack for an upward dihedral rotation. Symmetrically, an inward pointing hinge line leads to an increase in angle of attack with upward morphing. ${ }^{8,9}$ Twist evolution for different hinge flare angles is illustrated in Fig.3a, with an emphasis on the flare angle angle which is selected for this specific investigation. It is important to point out that higher hinge flare angles $\Lambda^{\text {hinge }}$ leads to greater twist modification $\Delta \theta$ for less deflection $\Gamma^{w t}$ of the tip, as illustrated in Fig. 3b. Therefore a hinge line with significant flare can lead to sufficient load alleviation for a given rotation limit. Given the scope of this research, a flare angle so as to have a hinge line perpendicular to the wing leading edge was selected. With a conventional swept wing, this ensures sufficient load alleviation for deflections up to $30^{\circ}$. The aircraft is assumed to be in a constant morphed configuration for each simulation.

The actuation dynamics of the device are also a critical aspect of the design. A spring-loaded actuator is considered to be an effective way of both unloading the wing under excessive gust or manoeuvre loads (clutch release) and restoring the wingtip after a high load incident (actuation). Nevertheless, the dynamics of the release are not considered at this stage of the investigation.

\section{Simulation set-up}

\section{A. Cranfield Accelerated Aeroplanes Loads Model}

The wingtip device is implemented within a MATLAB/Simulink based simulation framework known as Cranfield Aircraft Accelerated Loads Model $\left(\mathrm{CA}^{2} \mathrm{LM}\right)$. The $\mathrm{CA}^{2} \mathrm{LM}$ framework ${ }^{10}$ is an aeroservoelastic simulation framework capable of near real-time simulations. It couples both linear structural flexibility and unsteady aerodynamics in the time domain to capture aircraft flight dynamics and structural loads. The Matlab/Simulink based tool can also be used for handling quality investigations, and was previously used to study realistic pilot models, effect of manual controls on flexible structures ${ }^{11}$ and flight loads. ${ }^{12}$ The general architecture of the framework is given in Fig.4. Unsteady aerodynamics are based on a Modified Strip Theory coupled with time lag, flow build up effects, tail downwash and coupled with empirical fuselage, engine/nacelle and wing-body interaction modelling techniques from Empirical Scientific Data Units (ESDU). 


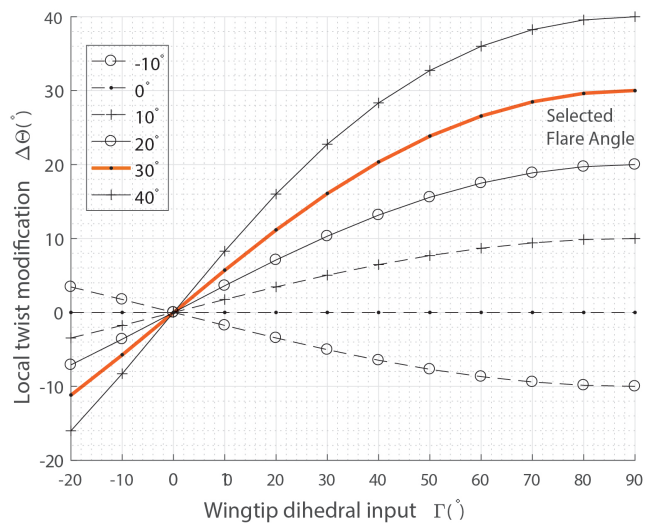

(a) Local twist modification with $\Gamma^{w t}$.

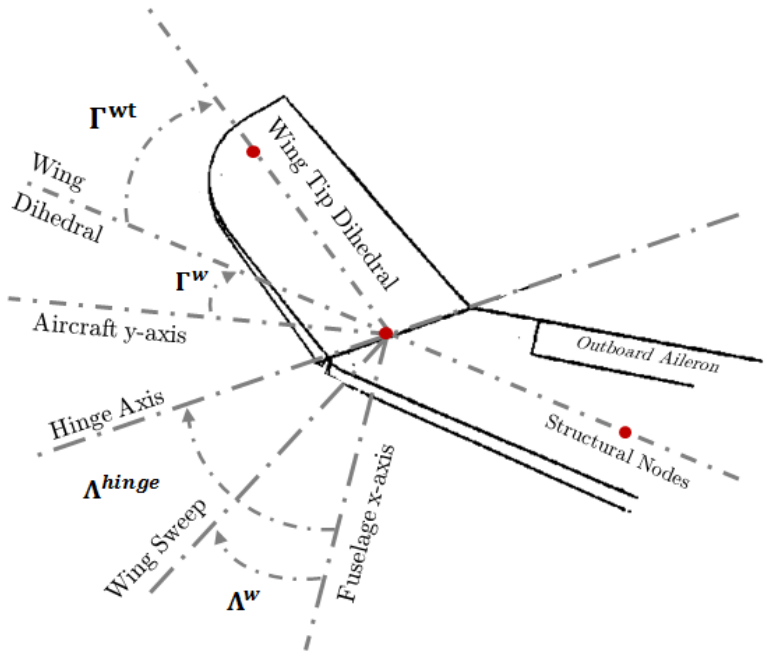

(b) Sketch of the morphing wingtip mechanism.

Figure 3: Morphing wingtip mechanism illustrations.

A modal approach is used to deform the complete aircraft structure under aerodynamic and inertial loading. Updated Centre of Gravity (CoG) positions are used to update aircraft positions, velocities and accelerations in all 6 Degrees of Freedom (DoF) using common Equations of Motion (EoM). Aircraft position is used in both gravity and atmospheric models to complete the simulation environment. For a more detailed description of the framework, the reader is referred to the dedicated literature. ${ }^{10,13,14}$

\section{B. Aircraft Specifications}

The aircraft selected for this investigation is the Cranfield University AX-1. Geometrical details of the aircraft are given in Fig.5, and Fig.6 illustrates the aircraft's specific mass, structural node and aerodynamic station distribution used to model and compute aircraft structural deformations, aerodynamic loading distribution and overall flight dynamics. Stiffness parameters of the wing structure are selected so as to emphasize the aeroservoelastic effects within the framework. A global structural damping of $3 \%$ is used with an additional aerodynamic damping contribution. The aircraft wingtip elastic deformation in cruise flight is below $10 \%$ of wing semispan, which is generally accepted as the limit to linear structural behaviour. A single mass case is discussed here at approximately $85 \%$ of Maximum Take-Off Weight (MTOW) with a Centre of Gravity $(\mathrm{CoG})$ at $25 \%$ of the mean aerodynamic chord. Both rigid and flexible structures will be compared so as to assess the impact of structural flexibility.

\section{Identification of Aerodynamic Derivatives}

\section{A. Simulation procedures}

A total of 300 simulations are conducted to capture the effect of different wingtip morphing on various flight conditions and aircraft configurations.

To capture the effect of wingtip morphing, a test matrix must be defined, along with the mechanism characteristics. Firstly, a fixed flare angle of $\Lambda^{\text {hinge }}=30^{\circ}$ is used, so as to have a hinge line perpendicular to the wing sweep angle. Hence, significant load alleviation can be achieved without requiring large deflections of the morphing device, as given by Fig.3a and Eqn.1. As the device is also intended to be released for loads alleviation, this leads to a released equilibrium point close to the baseline shape. Two different hinge line positions are considered, situated respectively at $10 \%$ and $20 \%$ wing semispan from the tip. With the current aircraft wing span, this corresponds respectively to $2.7 \mathrm{~m}$ and $5.4 \mathrm{~m}$ wingtip elements ${ }^{\mathrm{a}}$. For wingtip deflection, a discrete set of 7 wingtip angles $\Gamma^{w t}$ ranging from $0^{\circ}$ to $30^{\circ}$ with a $5^{\circ}$ step is used to cover

\footnotetext{
${ }^{a}$ In the $20 \%$ case, the wingtip is modelled with two beams rather than just one as in the $10 \%$ case.
} 


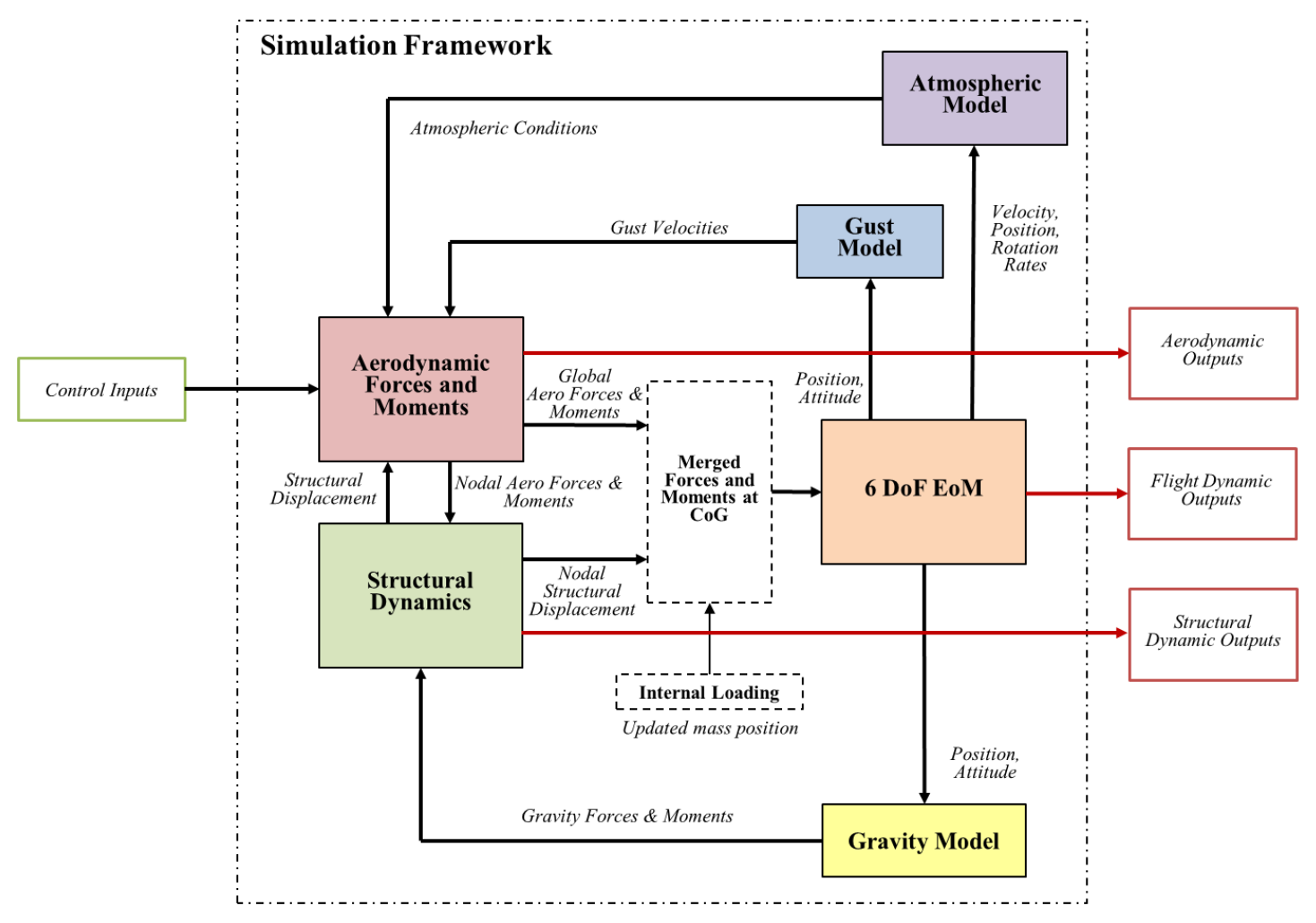

Figure 4: General architectural diagram of the $\mathrm{CA}^{2} \mathrm{LM}$ framework.

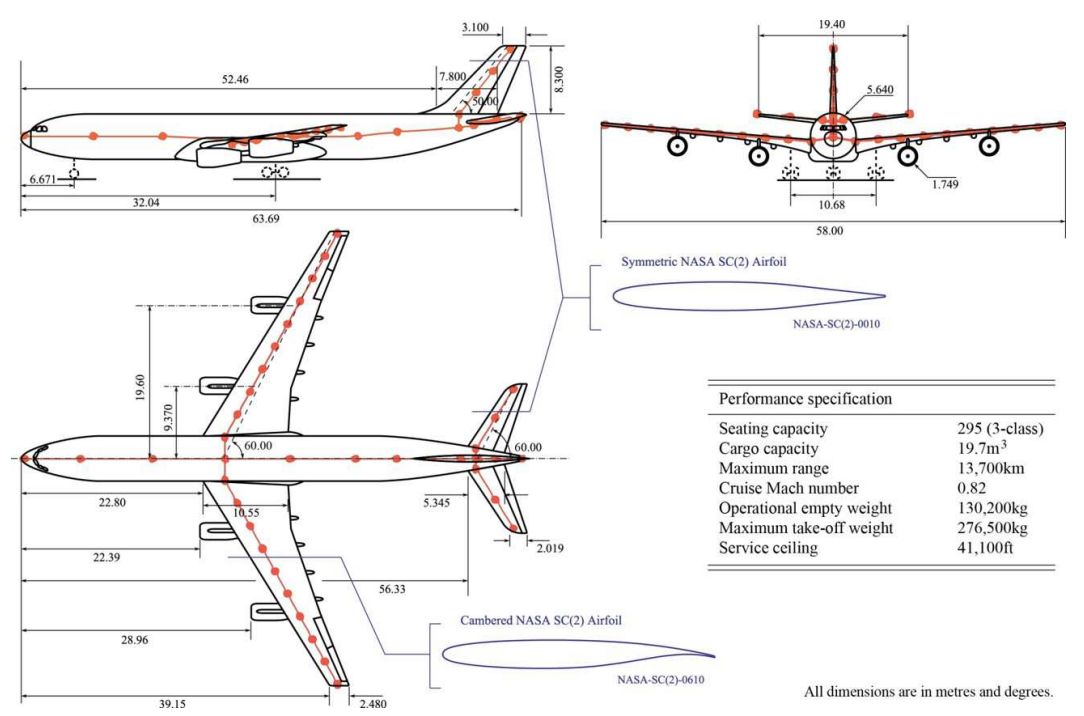

Figure 5: Cranfield University AX-1 large long range aircraft.

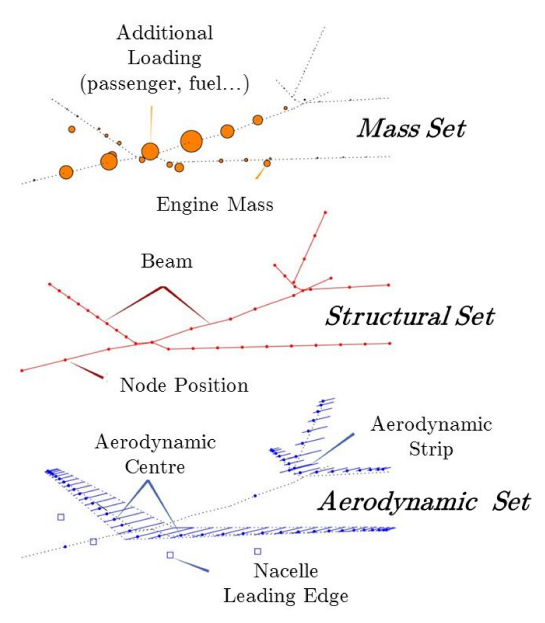

Figure 6: Discretised model

the capability of the system. Deflection is assumed to be symmetric on both wings. Both a loose hinge and controlled wingtip deflections are investigated. Due to framework modelling assumptions, the released wingtip case can only be modelled with the flexible airframe set-up.

Multiple airspeeds and altitudes within the flight envelope are selected for simulations. At each flight condition, the aircraft is trimmed in a baseline shape using conventional aircraft controls. When applying symmetric morphing input, a correction is applied using the elevator so as to balance the pitching moment 
induced by the deflected wingtips. The complete set of flight conditions is presented in Fig.7 with details given in Table 1.

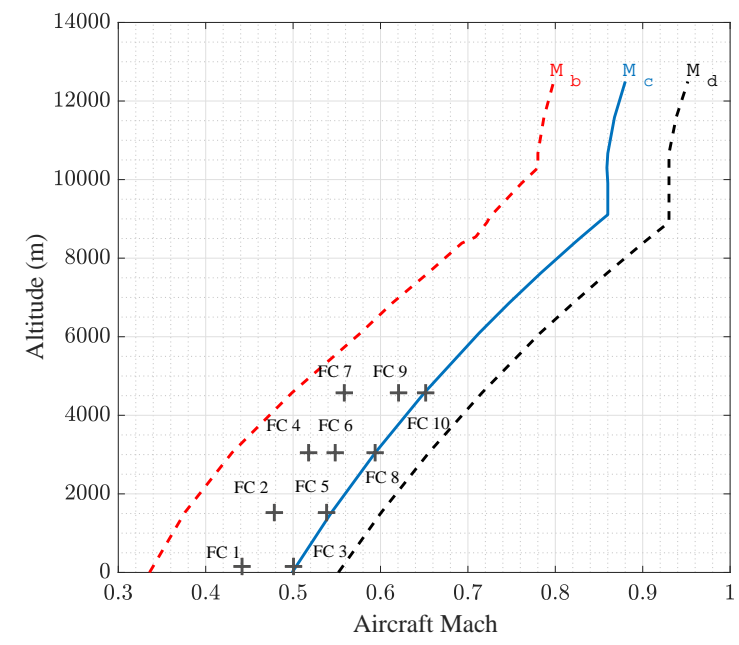

Figure 7: Selected flight conditions

\begin{tabular}{ccccc}
\hline \hline FC & TAS $\left(m . s^{-1}\right)$ & Alt. $(m)$ & Mach & $\bar{q}(\mathrm{~Pa})$ \\
\hline \hline 1 & 150 & 152.5 & 0.44 & 13613 \\
2 & 160 & 1525 & 0.48 & 13543 \\
3 & 170 & 152.5 & 0.5 & 17485 \\
4 & 170 & 3050 & 0.52 & 13103 \\
5 & 180 & 1525 & 0.54 & 17140 \\
6 & 180 & 3050 & 0.55 & 14690 \\
7 & 180 & 4575 & 0.56 & 12517 \\
8 & 195 & 3050 & 0.59 & 17240 \\
9 & 200 & 4575 & 0.62 & 15453 \\
10 & 210 & 4575 & 0.65 & 17037 \\
\hline \hline
\end{tabular}

Table 1: Flight condition details.

\section{B. Identification Procedure}

As the wingtip mainly affects the lateral dynamics of the aircraft, this paper will focus on aerodynamic derivatives such as $C_{l_{p}}$, rolling moment $l$ due to roll rate $p$ (roll damping), $C_{l_{\xi}}$, rolling moment $l$ due to aileron input $\xi$ (aileron effectiveness) and $C_{l_{\beta}}$, rolling moment $l$ due to sideslip $\beta$.

The equation of motion used to represent a small perturbation rolling manoeuvre is given by:

$$
\Delta \dot{p}-\frac{I_{x z}}{I_{x}} \Delta \dot{r}=L_{p} \frac{\Delta p b}{2 V}+L_{r} \frac{\Delta r b}{2 V}+L_{\beta} \Delta \beta+L_{\xi} \Delta \xi
$$

where:

$$
C_{l_{i}}=\frac{I_{x}}{\bar{q} S b} L_{i} ; \quad i=p, r, \beta, \xi
$$

Here $I_{x}$ and $I_{x z}$ represent the aircraft inertia with respect to x-axis and xz-plane respectively, $p$ and $r$ are aircraft roll and yaw rate, while $\beta$ is the side slip angle and $\xi$ represents aileron deflections. $L$ is the rolling moment dependent factor, and $C_{l}$ is the non-dimensional rolling moment. $q$ represents dynamic pressure, aircraft wing area is given by $S$, and wingspan $b$.

The reader should note that this equation focuses on the rigid body dynamics alone and neglects the aeroelastic effects.

Model parameters are identified using the ordinary least squares method, selected mainly due to its simplicity. The least square method tries to minimize the sum of squared differences between the measurements and the model. This approach requires the formulation of the following model equation:

$$
y=\mathbf{X} \theta
$$

and the following measurement equation:

$$
z=\mathbf{X} \theta+\nu
$$

where $z \in \mathbb{R}^{N \times 1}, \theta \in \mathbb{R}^{n_{p} \times 1}, \mathbf{X} \in \mathbb{R}^{N \times n_{p}}$ and $\nu \in \mathbb{R}^{N \times 1}$. The parameter vector $\theta$ is obtained by minimising the following cost function:

$$
J(\theta)=\frac{1}{2}[z-\mathbf{X} \theta][z-\mathbf{X} \theta]^{T}
$$

such that

$$
\hat{\theta}=\left(\mathbf{X}^{T} \mathbf{X}\right)^{-1} \mathbf{X} z
$$


In this case, the measurement equation is defined as:

$$
z=\dot{p}-\frac{I_{x z}}{I_{x}} \dot{r}
$$

while the regressor matrix for $\mathrm{N}$ number of data, and the parameter are defined as :

$$
\begin{gathered}
X=\left[\begin{array}{cccc}
\frac{b}{2 V} p(1) & \frac{b}{2 V} r(1) & \Delta \beta(1) & \delta \xi(1) \\
\vdots & \vdots & \vdots & \vdots \\
\frac{b}{2 V} p(N) & \frac{b}{2 V} r(N) & \Delta \beta(N) & \delta \xi(N)
\end{array}\right] \\
\theta=\left[\begin{array}{llll}
L_{p} & L_{r} & L_{\beta} & L_{\xi}
\end{array}\right]^{T}
\end{gathered}
$$

Details on the methods formulation can be found in the relevant referenced documents. ${ }^{15,16}$ The estimation routine was built through the use of the lesq function within the SIDPAC library. ${ }^{16}$ An aileron pulse input was used to introduce aircraft rolling motions. A low deflection amplitude of sufficient time ensures that maximum roll rate is achieved before large attitude changes are introduced. This ensures that despite being open-loop, the simulation outputs corresponds to small perturbations around the specific trim or equilibrium point, hence respecting the assumptions of the model being identified.

\section{Results}

Results presented in this paper are organised following two main sections dedicated respectively to the rigid airframe and the flexible aircraft where aircraft roll damping coefficient $C_{l_{p}}$, aircraft aileron effectiveness $C_{l_{\xi}}$, as well as the roll coefficient due to sideslip angle $C_{l_{\beta}}$ are investigated for two wingtip sizes. From the results of these 300 simulations, covering 10 different flight conditions, two separate trends were identified. The trends are related to aircraft dynamic pressure and trim angle-of-attack. Hence, the analysis presented in this paper will focus on two subgroups of flight conditions. The first subgroup includes FCs 1, 2, 4, and 7 where the aircraft was trimmed at positive trim angle-of-attack and low-dynamic pressures. The second group includes FCs 3, 8, and 10, which corresponds to a negative trim angle-of-attack and high dynamic pressures.

\section{A. Rigid Aircraft}

In the following discussion, it is important to note that the aircraft structure is assumed to maintain the trimmed flight shape throughout the simulations. Thus, wingtip morphing does not affect the dynamic wing deformation.

It can be seen from Fig.9a to Fig.9f, that the smaller wingtip size of $10 \%$ semispan leads to minimal changes in the lateral aerodynamic derivatives $C_{l_{p}}, C_{l_{\xi}}$, whilst more notable shifts are introduced in $C_{l_{\beta}}$. Minor changes to $C_{l_{p}}$ and $C_{l_{\xi}}$ are justified by the relatively small lift and drag contribution of the wingtip. On the other hand, as the wingtip deflects, the equivalent vertical surface area increases significantly relative to the baseline configuration and the deflected wingtip contributes to the overall tail volume ratio. This leads to a greater $C_{l_{\beta}}$ coefficient, or sideslip contribution in roll dynamics. This is shown in Fig.9e and Fig.9f. It should also be noted that this effect is more significant at lower dynamic pressures, where a linear trend can be identified. At higher dynamic pressures, a non-linear trend is introduced, with a notable reverse with higher morphing angles $\Gamma$.

Increasing wingtip size to $20 \%$ semispan introduces shifts in $C_{l_{p}}, C_{l_{\xi}}$ and $C_{l_{\beta}}$ of greater amplitude as shown in Fig.10a to Fig.10f. With a greater impact on the total lift and drag and respective distributions, the aircraft roll damping coefficient decreases as span and outboard lift is reduced by morphing. Similarly, $C_{l_{\xi}}$ is reduced as the hinge line of the folding mechanism is now coinciding with the outboard aileron limit. Hence the effective lift and aileron efficiency is reduce. Lastly, changes in $C_{l_{\beta}}$ are the most prominent; with an increase of up to $40 \%$. With the larger wingtip, the effect underlined with the smaller wingtip is confirmed, with larger changes to $\Delta C_{l_{\beta}}(\Gamma)$. This increase was expected with increased equivalent vertical aerodynamic surface per deflection angle. On the other hand, these changes are more important at higher dynamic pressures. A near linear trend can be identified for $\Delta C_{l_{\beta}}(\Gamma)$. Hence, the size of the wingtip mechanism 
significantly changes the shift in aerodynamic derivative amplitude, both as a function of flight condition and dihedral morphing angle.

Time histories comparing the effect of morphing wingtips on aircraft response are illustrated in Fig.8a and Fig.8b, where both subgroups are represented at a single flight condition. With lower sideslip values in the deflected wingtip configuration and similar rolling moments and roll rates, it can be seen that $C_{l_{\beta}}$ increases. Similarly, the decrease in $C_{l_{p}}$ is highlighted by a larger roll angles at the end of the simulation. In the larger wingtip case, decrease in $C_{l_{p}}$ and $C_{l_{\xi}}$ are highlighted by the minor offset in both roll rate and roll angle.
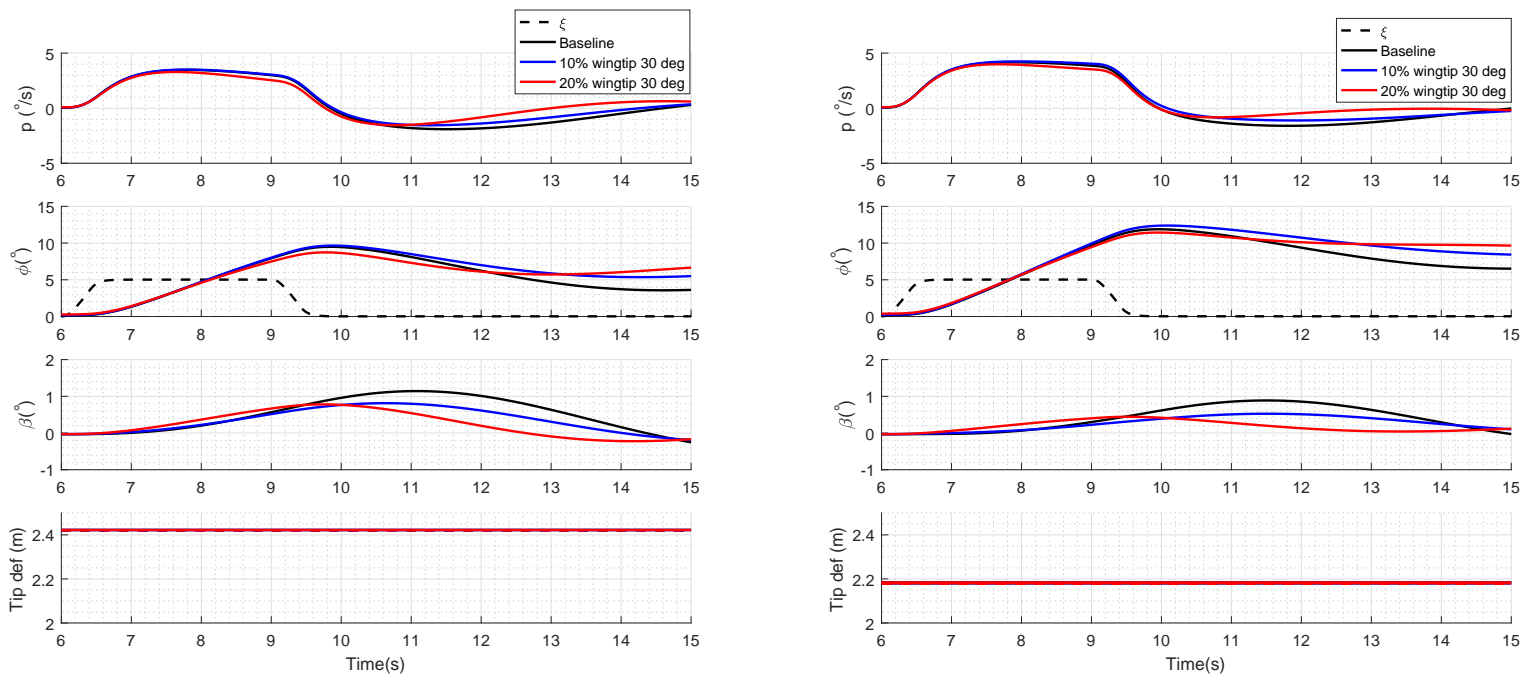

(a) Flight Condition 1

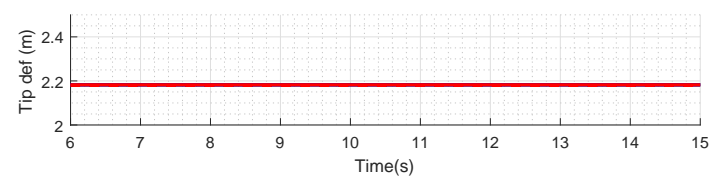

(b) Flight Condition 3

Figure 8: Variations of aircraft time histories with morphing angle of a rigid aircraft with $10 \%$ and $20 \%$ semispan wingtip device.

\section{B. Flexible Aircraft}

The aircraft's high wing span and airframe flexibility leads to significant changes on overall flight dynamics during the manoeuvre. With a flexible wing, the structure deforms in response to both wingtip morphing and manoeuvre loads. So different values of $C_{l_{p}}, C_{l_{\xi}}$ and $C_{l_{\beta}}$ are obtained as the airframe deforms due to aerodynamic loading. The dynamics of a released fold mechanism, or loose wingtip, are also included in this comparison to capture possible features of interest or failure cases.

The baseline aerodynamic derivatives inevitably change as airframe flexibility is introduced in the simulation. Flexibility or aeroelastic effects were found to decrease roll damping $C_{l_{p}}$. Aileron effectiveness $C_{l_{\xi}}$ also reduces with dynamic pressure, as the wing structure is allowed to deform under aerodynamic loading and countering the effect of aileron deflection. The value of $C_{l_{\beta}}$ remains fairly similar.

Fig.12a to Fig.12f illustrate the shift in aerodynamic derivatives for the flexible airframe with a wingtip device of $10 \%$ wingtip semispan. It is evident that $\Delta C_{l_{p}}(\Gamma)$ is more important at higher dynamic pressures. Shifts are kept relatively low, with a maximum increase of $6 \%$ relative to the baseline value. Here, the inclusion of aeroelastic effects shows that $C_{l_{p}}$ increases as a function of wingtip morphing angle $(\Gamma) . \Delta C_{l_{\xi}}(\Gamma)$ and $\Delta C_{l_{\beta}}(\Gamma)$ are also very small. In fact, changes due to flight conditions are more intense than those introduced due to morphing. Even in the case of a released wingtip or actuation failure, response to a roll input is not too different from the baseline configuration.

The extended wingtip device at $20 \%$ wingspan also displays interesting behaviours, illustrated in Fig.13a to Fig.13f. Where very little changes in roll damping coefficient are found in controlled morphing, the shift in $C_{l_{p}}$ and $C_{l_{\xi}}$ in the loose scenario reaches up to a $10 \%$ decrease for the lower dynamic pressures (similar to landing or take-off conditions). $\Delta C_{l_{\beta}}$ is unremarkable both in controlled and released configurations. At higher aerodynamic pressures, the released wingtip configuration shows smaller shifts, and therefore changes to aircraft lateral dynamics. Overall, the larger shifts in aerodynamic derivatives are introduced at lower 

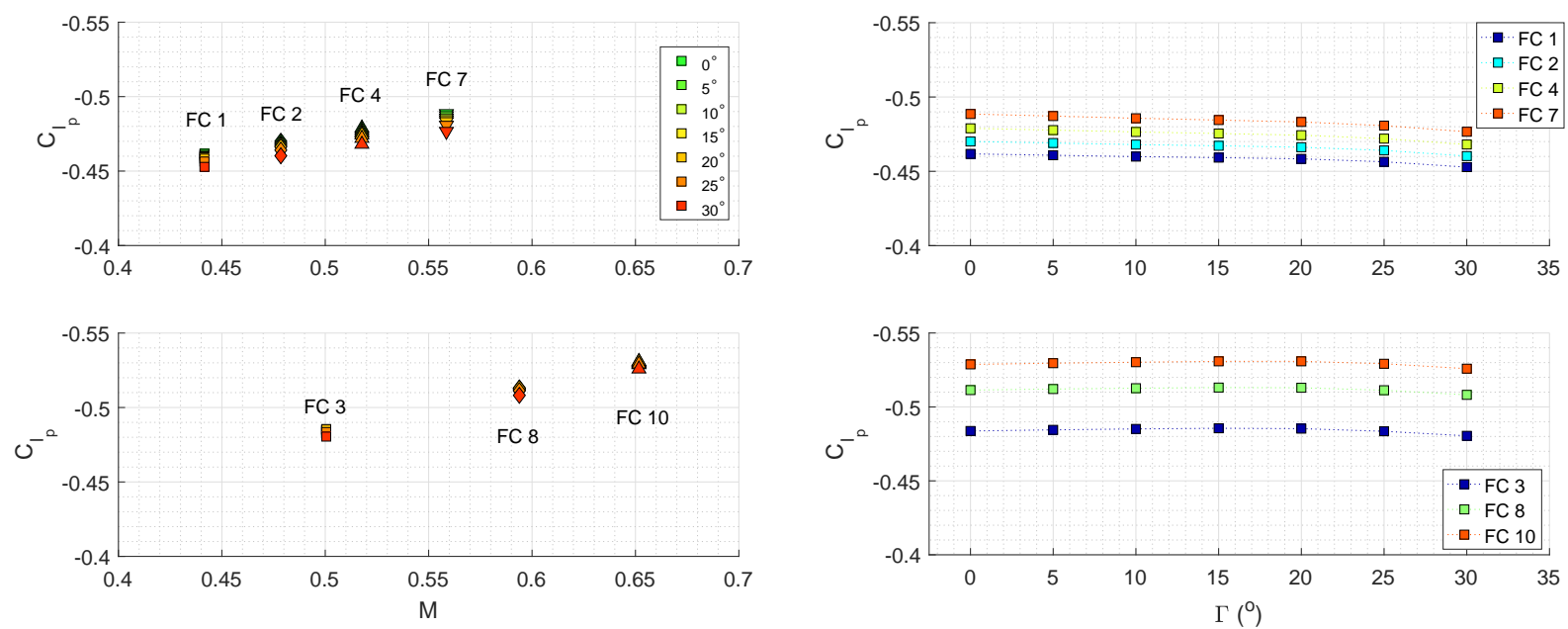

(a) $C_{l_{p}}(\mathrm{M})$

(b) $C_{l_{p}}(\Gamma)$
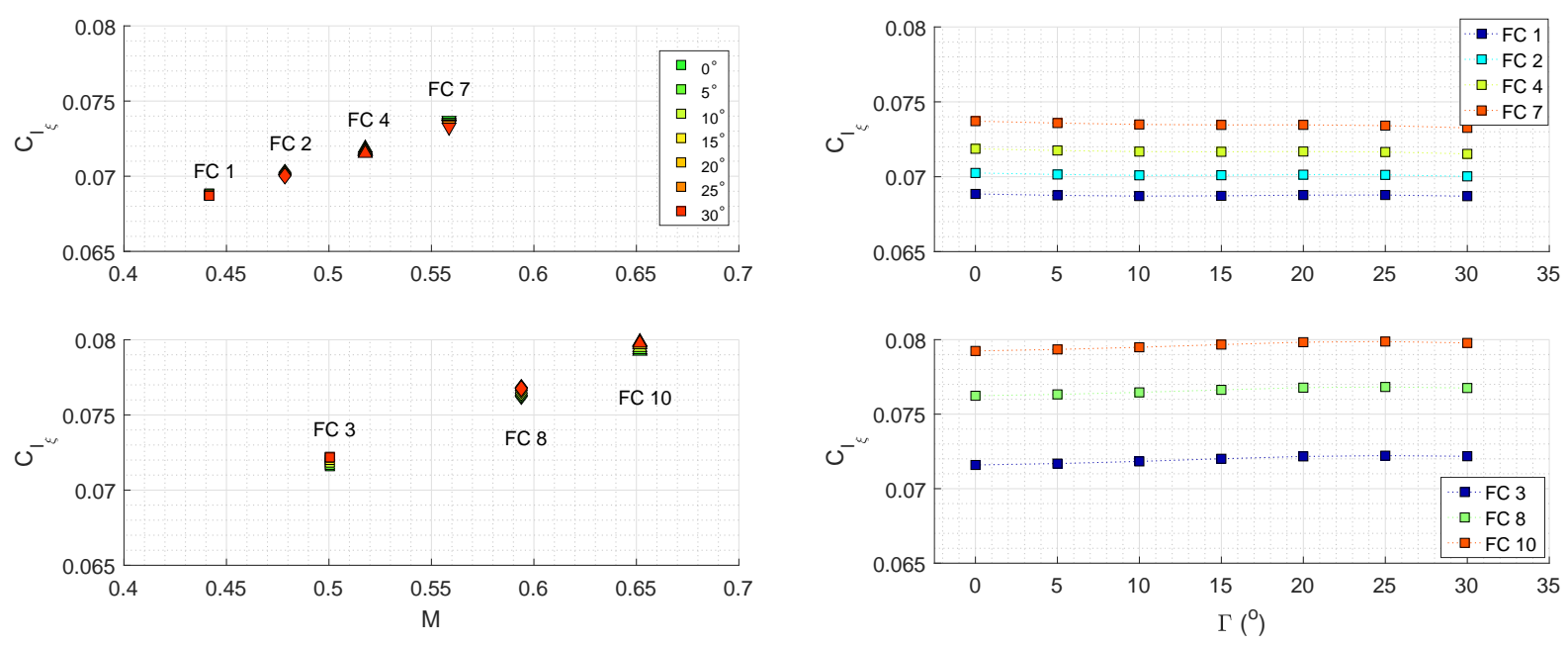

(c) $C_{l_{\xi}}(\mathrm{M})$

(d) $C_{l_{\xi}}(\Gamma)$
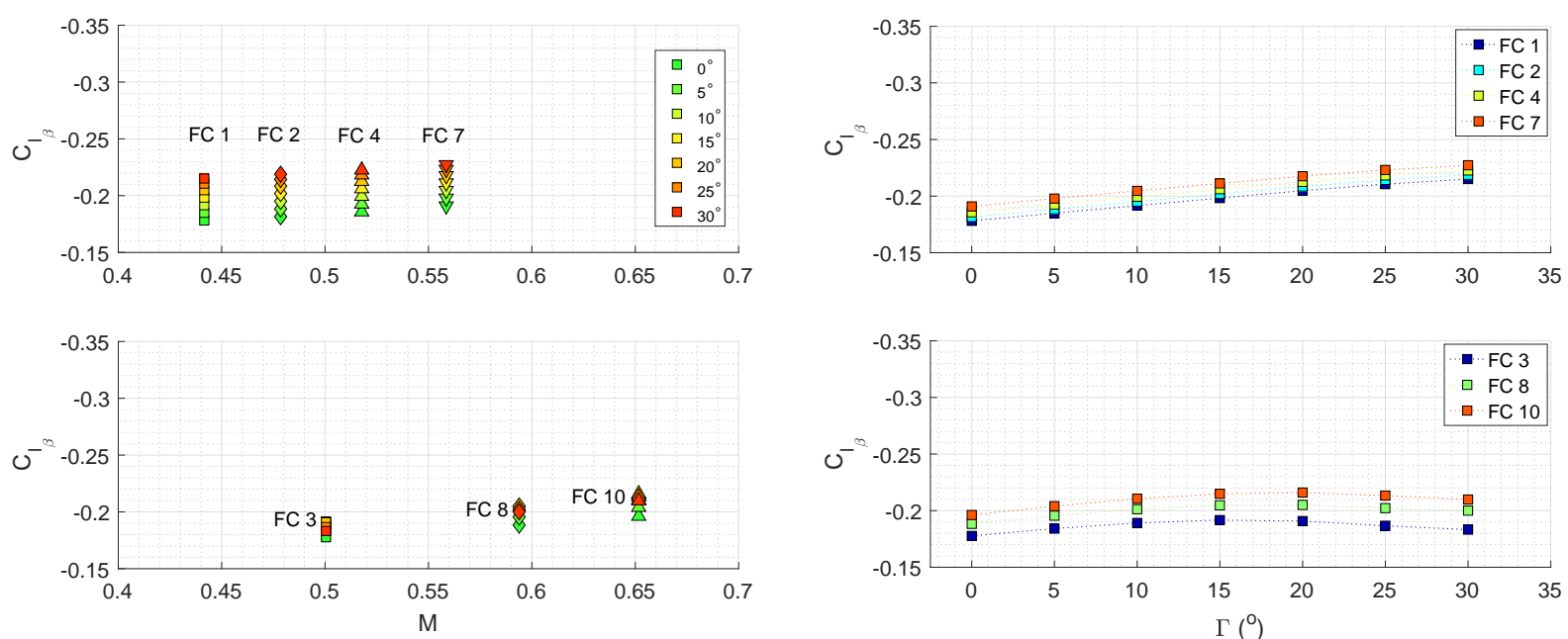

(e) $C_{l_{\beta}}(\mathrm{M})$

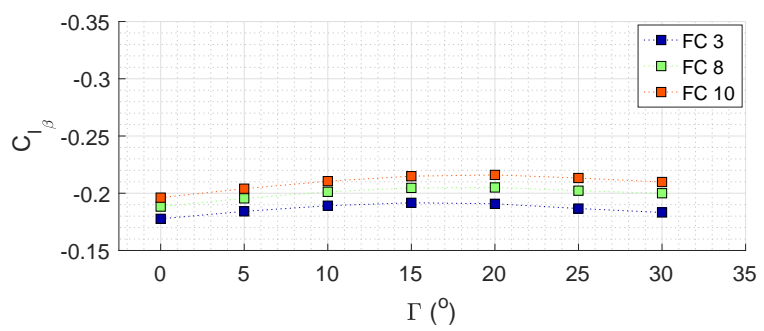

(f) $C_{l_{\beta}}(\Gamma)$

Figure 9: Variations with flight condition and morphing angle for rigid aircraft with $10 \%$ semispan wingtip device. 

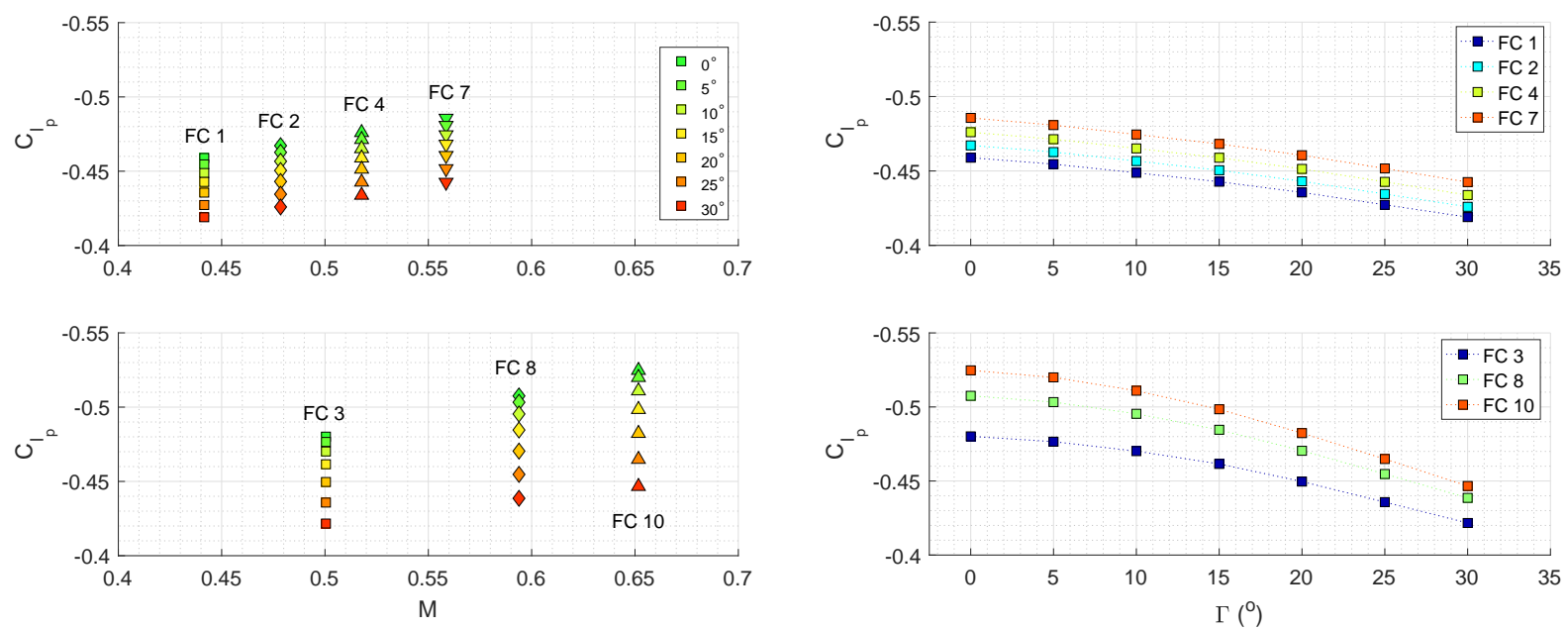

(a) $C_{l_{p}}(\mathrm{M})$

(b) $C_{l_{p}}(\Gamma)$
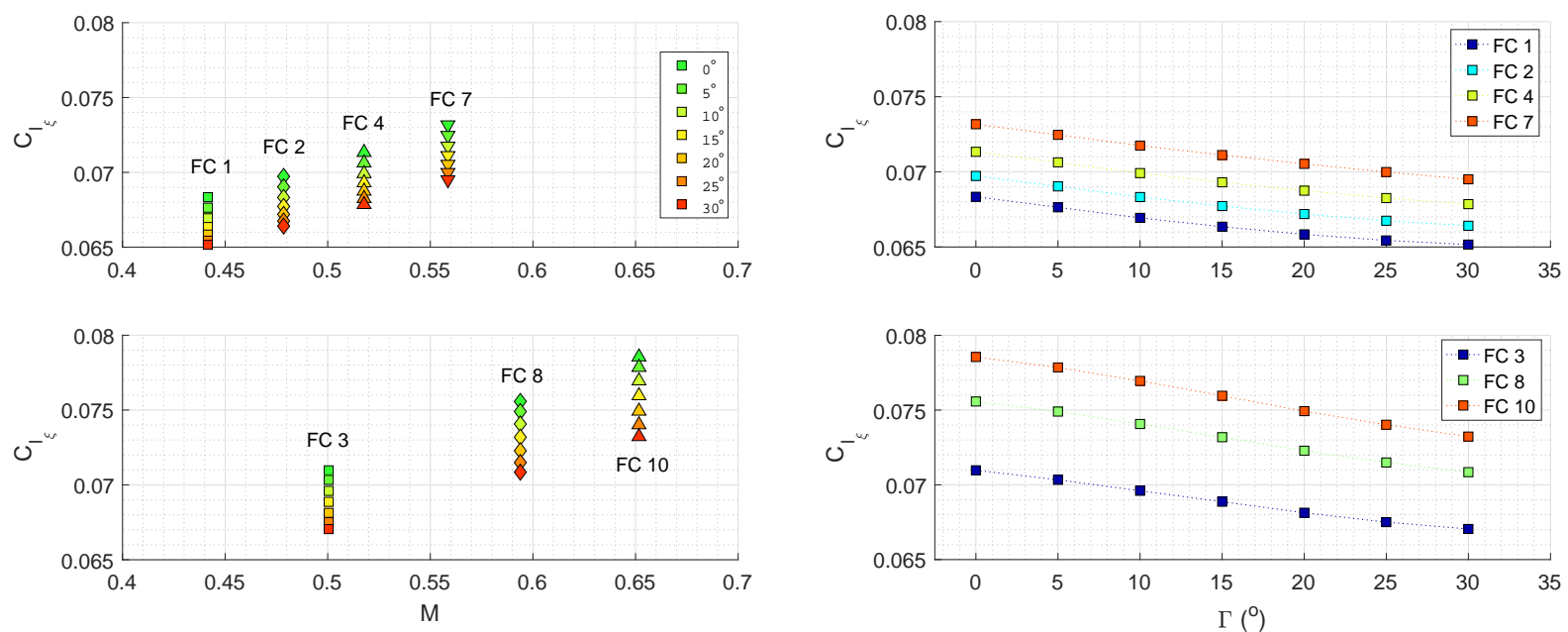

(c) $C_{l_{\xi}}(\mathrm{M})$

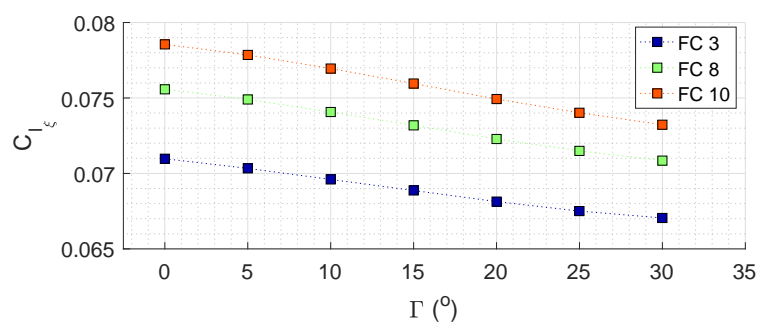

(d) $C_{l_{\xi}}(\Gamma)$
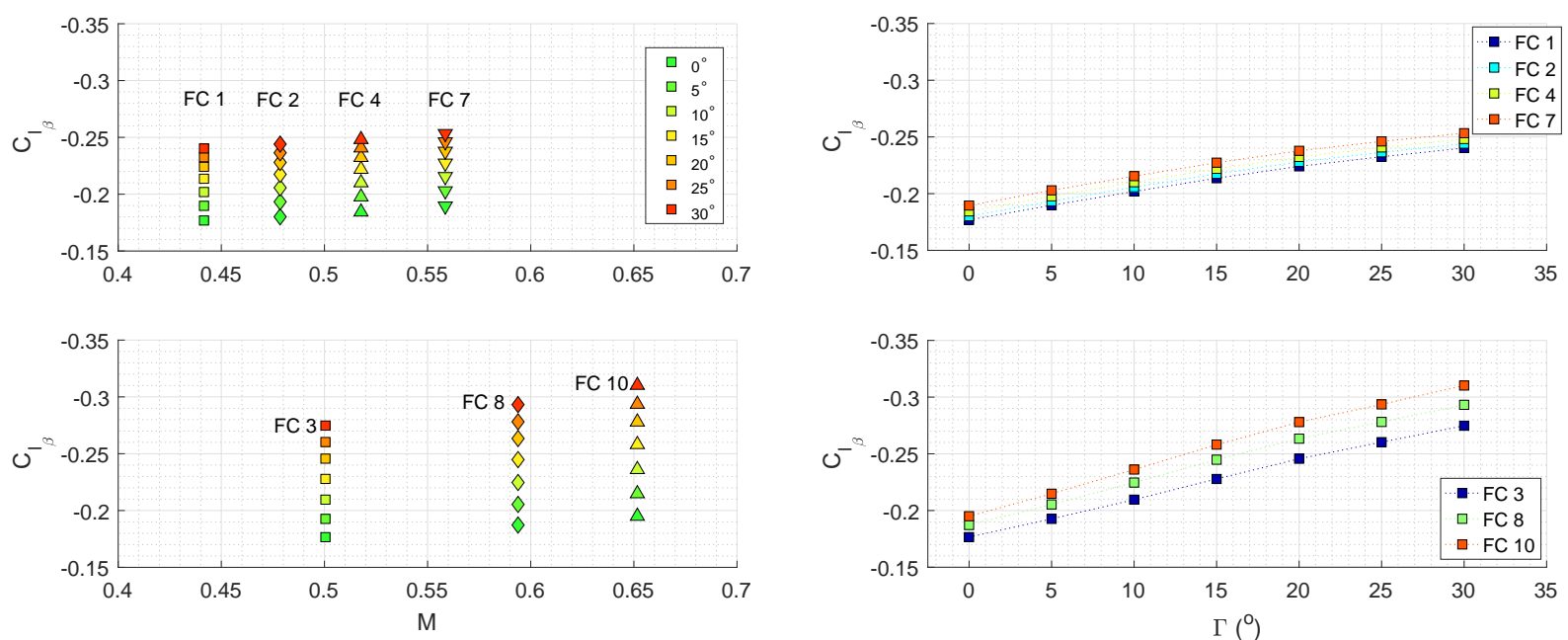

(e) $C_{l_{\beta}}(\mathrm{M})$

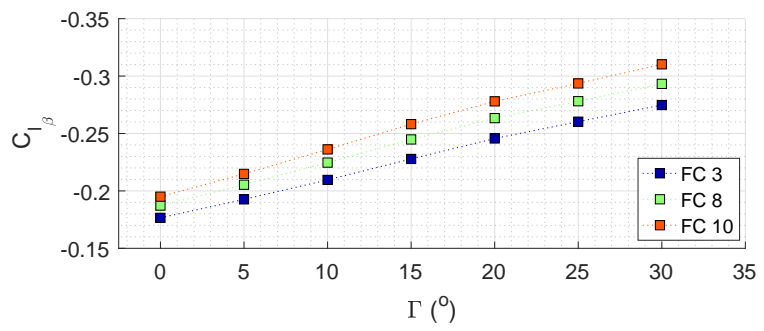

(f) $C_{l_{\beta}}(\Gamma)$

Figure 10: Variations with flight condition and morphing angle for rigid aircraft with $20 \%$ semispan wingtip device. 
dynamic pressures, with relatively low amplitudes from the baseline aircraft configuration. As the wing structure deflects under morphing, it was found that flexibility minimises the impact of an in-flight folding wingtip, with changes in trends due to morphing and flight conditions when compared to the rigid results.

Time histories comparing the effect of morphing wingtips on aircraft response are illustrated in Fig.11a and Fig.11b, where both subgroups are studied at a single flight condition. Similar to the rigid body configuration, larger wingtip size resulted in smaller sideslip and higher roll angles, which is in line with the increasing value of $C_{l_{\beta}}$, and decreasing value of $C_{l_{p}}$. Tip deflections provided in both plots illustrate the projected wingtip position without the vertical offset due to rotation, quantifying the overall downward deflection of the wing with morphing and wingtip size.
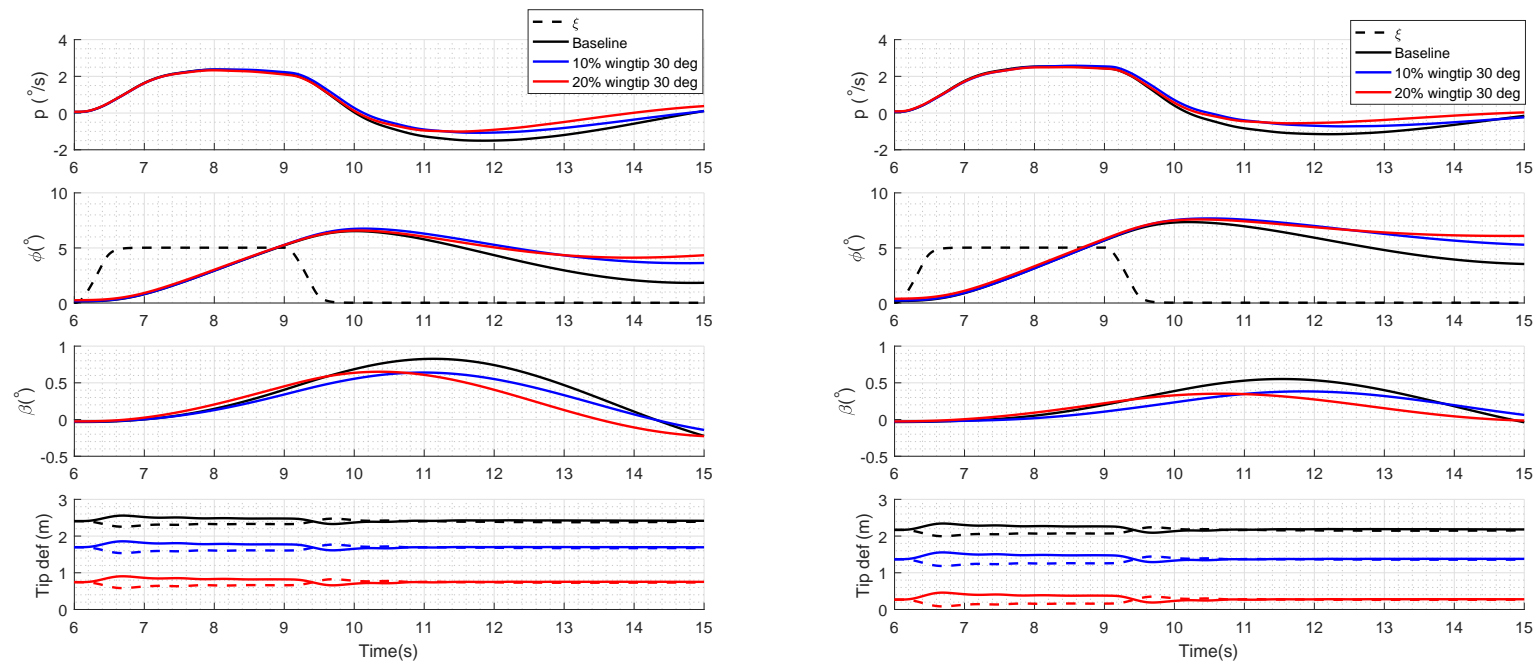

(a) Flight Condition 1

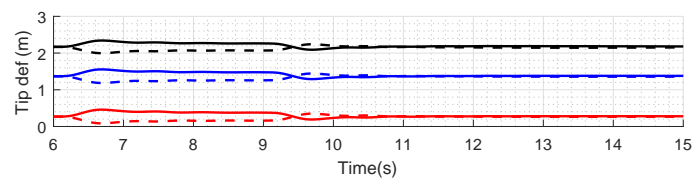

(b) Flight Condition 3

Figure 11: Variations of aircraft time histories with morphing angle of a flexible aircraft with $10 \%$ and $20 \%$ semispan wingtip device.

\section{Prediction model derivation}

In order to use the above mentioned results, these can be implemented directly in an aerodynamic derivative based flight simulator. This requires a significant data transfer and implementation process. Another alternative is to implement a prediction model to account for the effect of dihedral wingtip morphing on the aerodynamic derivatives. This prediction model would be built around the baseline unmorphed rigid body configuration at each flight condition. The difference or shift between baseline and morphed configurations can be parametrised as a function of flight conditions and morphing angle. These functions would therefore predict the appropriate shift or $\Delta C_{l}$ without the need of a complete and extensive database. From the findings presented in Section V, prediciton models are proposed in the following formulation:

$$
\begin{aligned}
& C_{l_{p}}^{\Gamma}=C_{l_{p}}^{\Gamma=0, \text { rigid }}\left(1+\Delta C_{l_{p}}^{\text {flex }}+\Delta C_{l_{p}}^{\Gamma}(\Gamma, \alpha)\right) \\
& C_{l_{\xi}}^{\Gamma}=C_{l_{\xi}}^{\Gamma=0, \text { rigid }}\left(1+\Delta C_{l_{\xi}}^{\text {flex }}+\Delta C_{l_{\xi}}^{\Gamma}(\Gamma, \alpha)\right)
\end{aligned}
$$

A prediction model derived for the rigid configuration with a $20 \%$ semispan wingtip device is presented in Eqn.12 and Eqn.13. The comparison for the correction model and identification results are given in Fig.14. These models were obtained using a multi-orthogonal identification approach. ${ }^{16}$ It was found that a suitable function to predict aerodynamic derivative changes could be found and parametrised as a function of both angle of attack and wingtip morphing. $\Gamma$ and $\alpha$ for the following equation must be in radians. This model is valid only for the first subgroup at lower dynamic pressures, as different behaviours were highlighted for the 

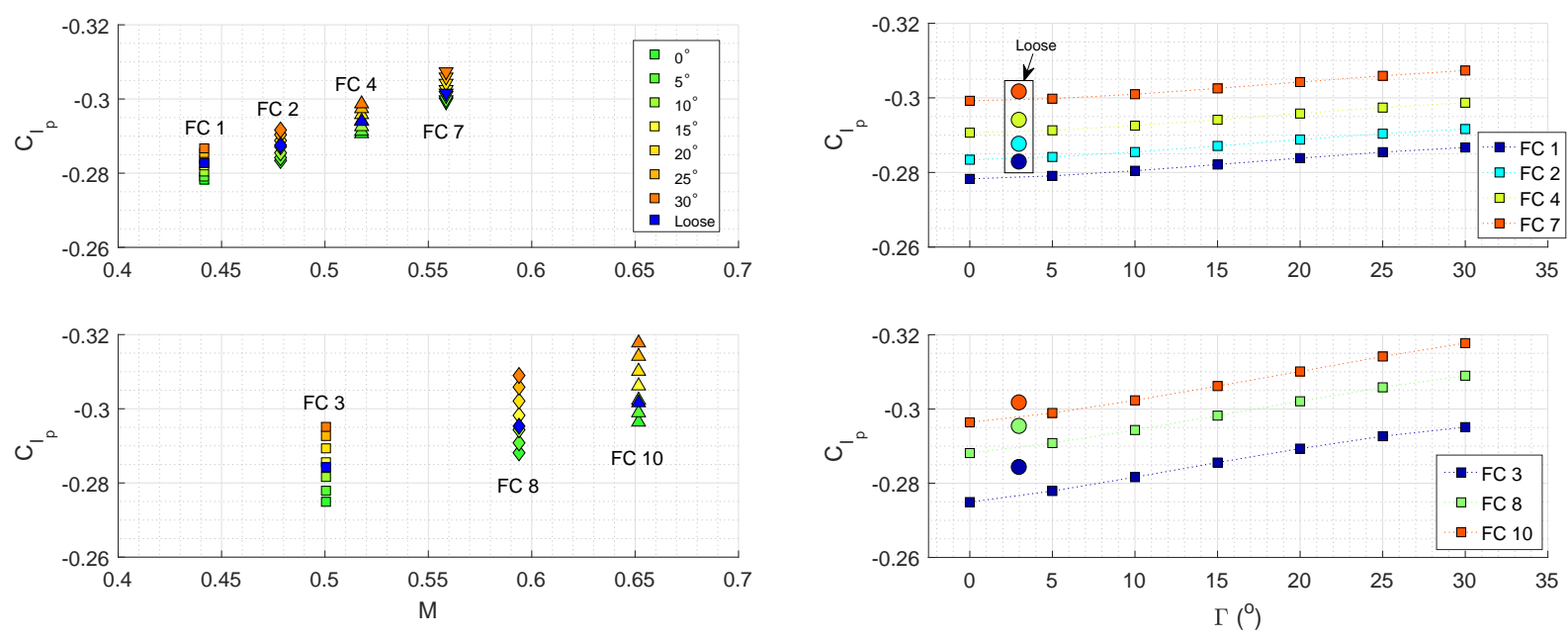

(a) $C_{l_{p}}(\mathrm{M})$

(b) $C_{l_{p}}(\Gamma)$
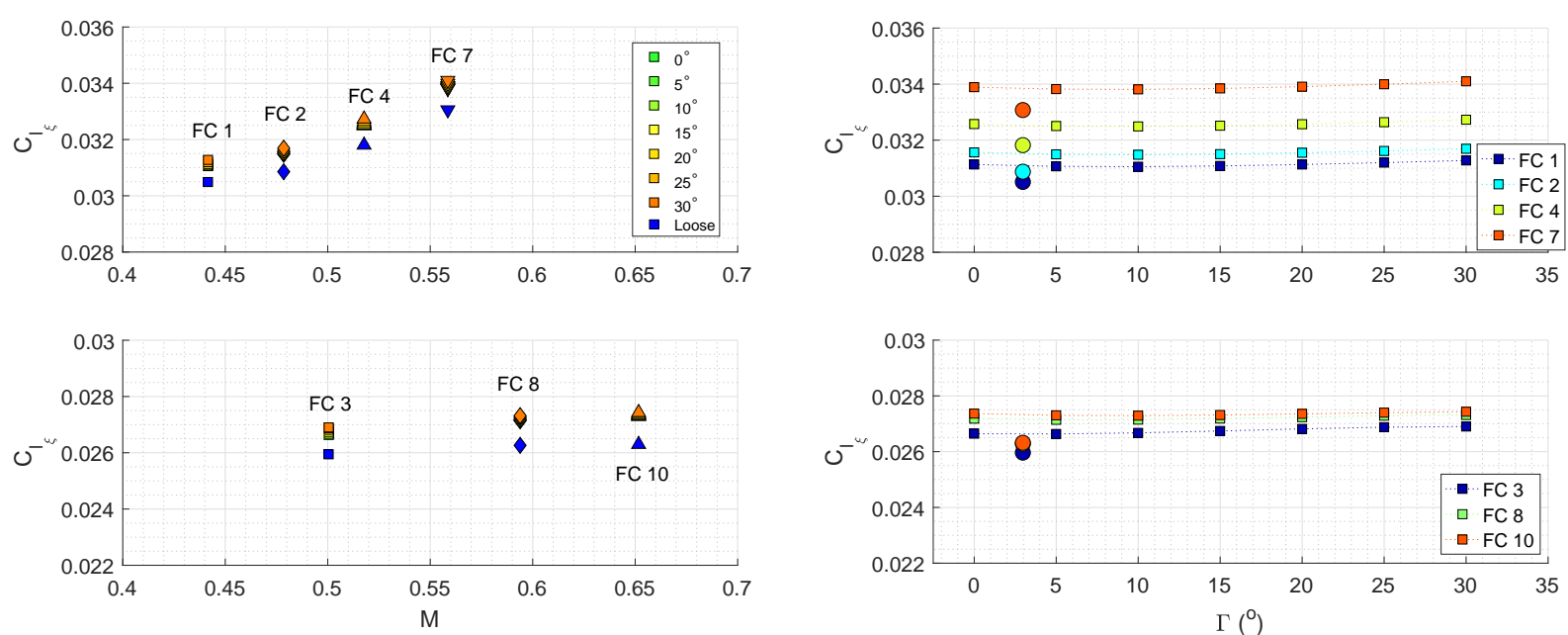

(c) $C_{l_{\xi}}(\mathrm{M})$

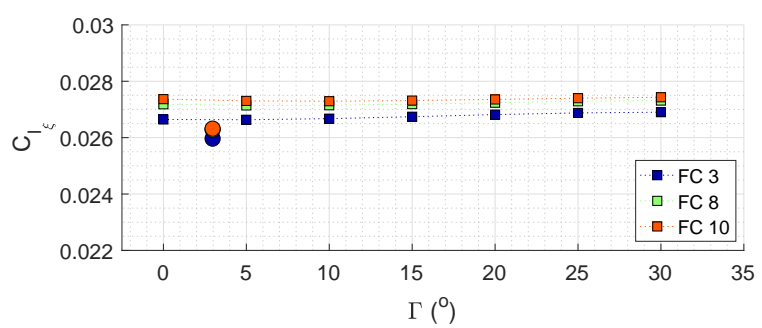

(d) $C_{l_{\xi}}(\Gamma)$
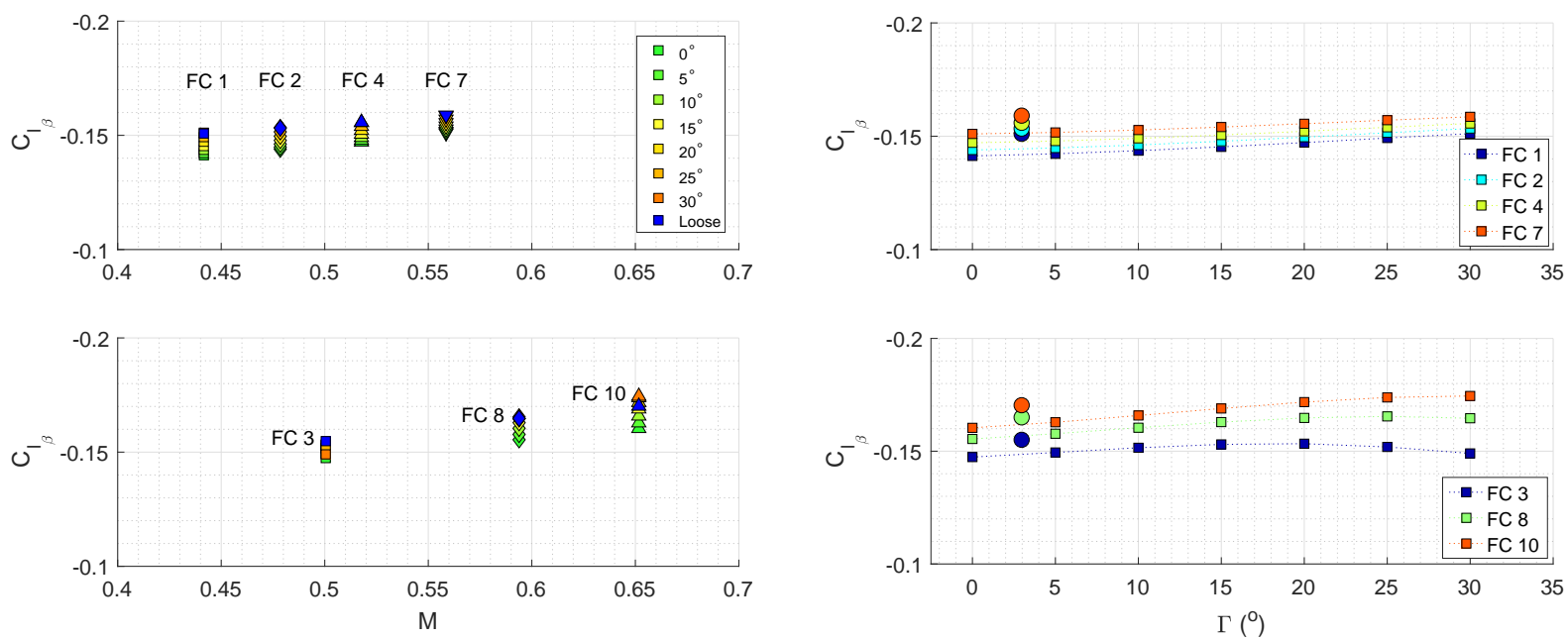

(e) $C_{l_{\beta}}(\mathrm{M})$

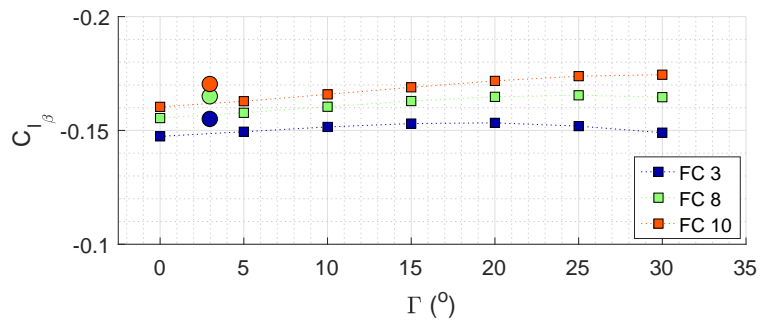

(f) $C_{l_{\beta}}(\Gamma)$

Figure 12: Variations with flight condition and morphing angle for flexible aircraft with $10 \%$ semispan wingtip device. 

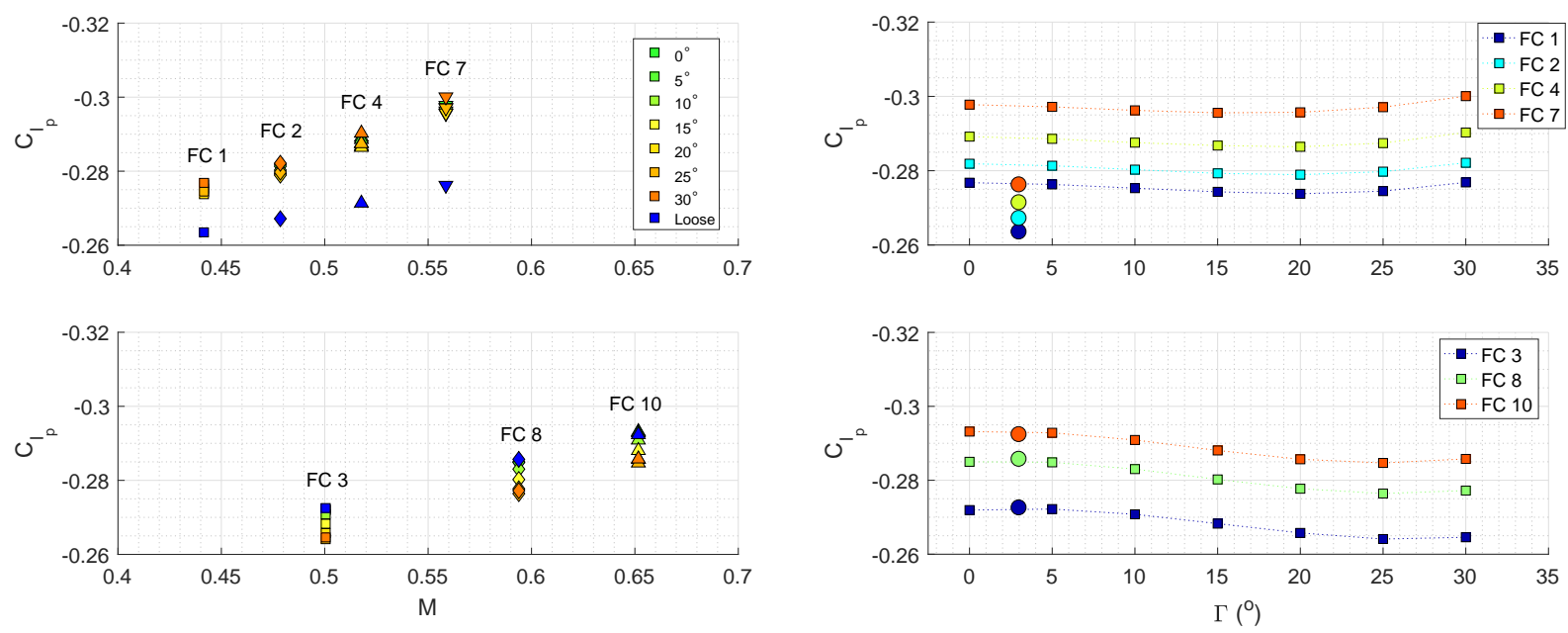

(a) $C_{l_{p}}(\mathrm{M})$

(b) $C_{l_{p}}(\Gamma)$
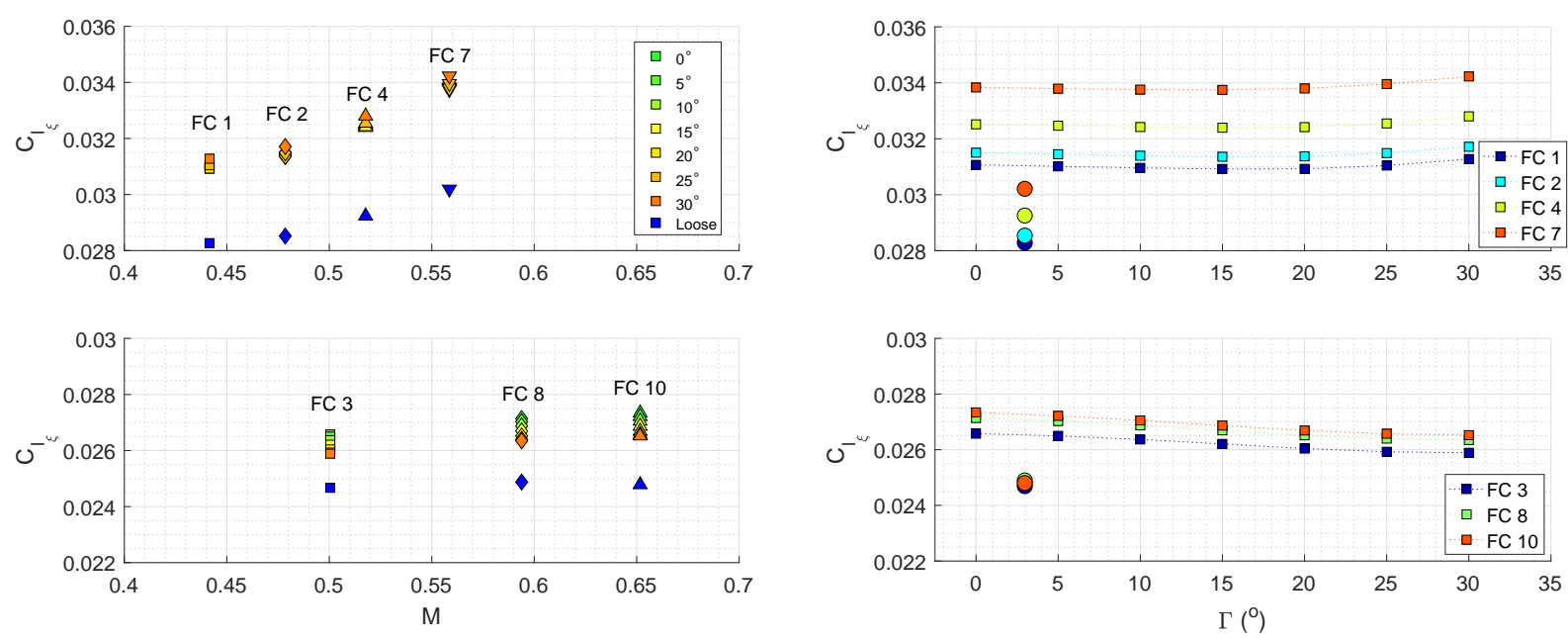

(c) $C_{l_{\xi}}(\mathrm{M})$

(d) $C_{l_{\xi}}(\Gamma)$
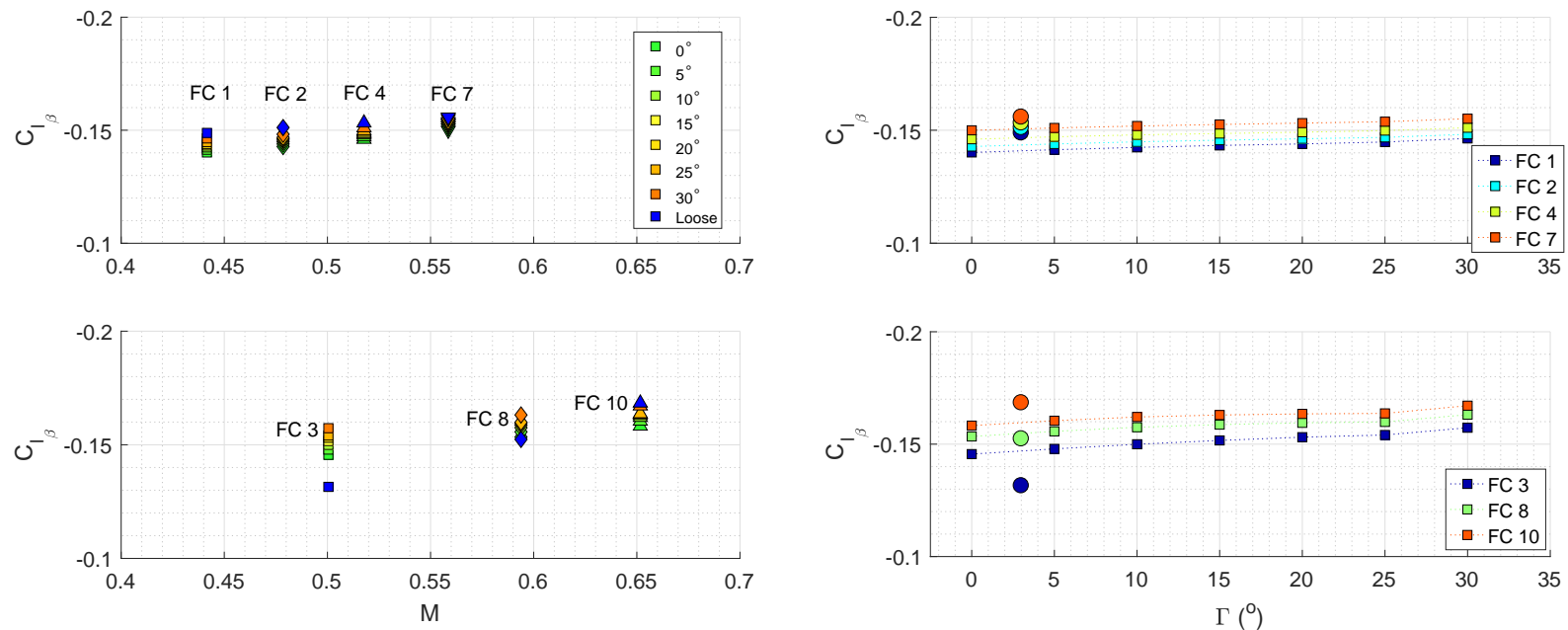

(e) $C_{l_{\beta}}(\mathrm{M})$

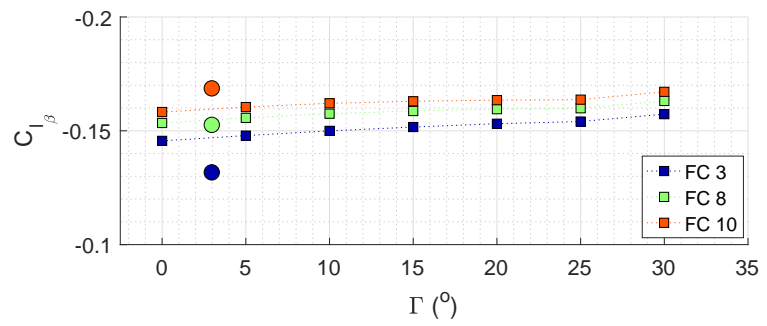

(f) $C_{l_{\beta}}(\Gamma)$

Figure 13: Variations with flight condition and morphing angle for flexible aircraft with $20 \%$ semispan wingtip device. 
higher dynamic pressure cases. Different coefficients were identified for other flight conditions and wingtip sizes.

$$
\begin{aligned}
& C_{l_{p}}^{\Gamma}=C_{l_{p}=0}^{\Gamma=0}(1-5.30 \alpha \Gamma) \\
& C_{l_{\xi}}^{\Gamma}=C_{l_{\xi}}^{\Gamma=0}(1-0.117 \Gamma)
\end{aligned}
$$

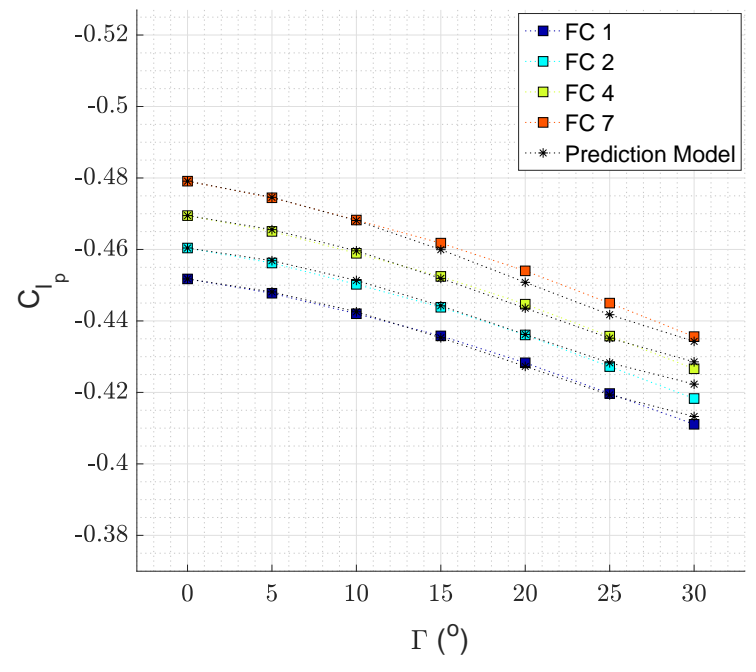

(a) Roll damping model

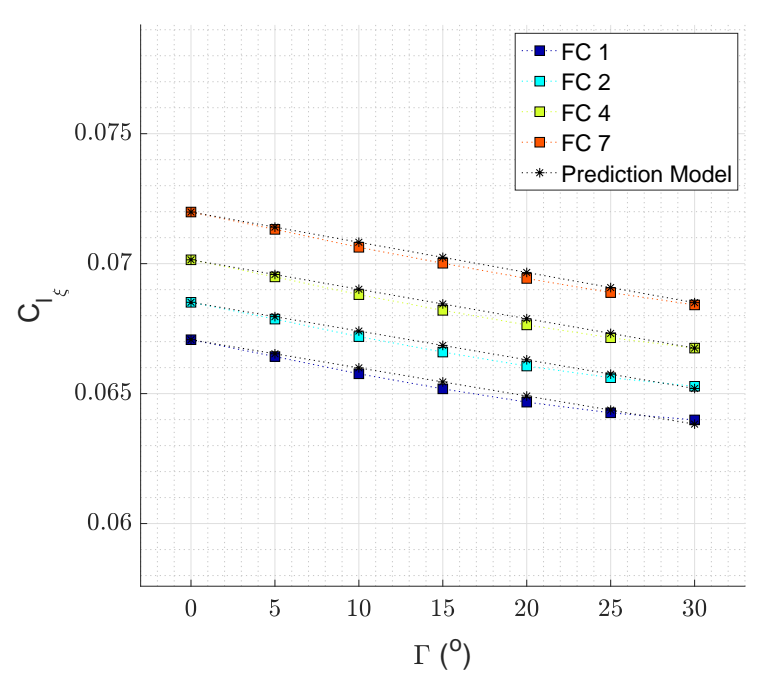

(b) Aileron effectiveness model

Figure 14: Comparison of the prediction model and identification results, for rigid aircraft with $20 \%$ semispan wingtip device.

\section{Conclusions and Further Work}

The impact of a morphing wingtip mechanism on the roll dynamics of a generic aircraft has been investigated in this paper. Results from applying parameter identification to an aeroservoelastic simulation framework have shown trends in key aerodynamic derivatives with respect to wingtip morphing, namely roll damping $C_{l_{p}}$, aileron effectiveness $C_{l_{\xi}}$ and roll due to sideslip $C_{l_{\beta}}$. The shift in aerodynamic derivatives was influenced by wingtip size (or hinge position relative to wing semispan) and airframe flexibility. In the latter case, the wing flexibility leads to a reversed trend in roll damping coefficient with respect to morphing angle and dynamic pressure.

Overall, changes to the aerodynamic derivatives are found to be relatively low. These results indicate that in the case of controlled morphing, failure or undesired morphing, the aircraft response stays fairly similar to that of the baseline configuration. This study has therefore, shown that such devices do not pose major challenges or risks from the perspective of lateral handling qualities. Nevertheless, pilot-in-the-loop simulations are still required to obtain more thorough handling qualities results.

For that purpose, an aerodynamic derivative database was generated for multiple flight conditions, ready to be added to the aerodynamic database of a flight simulator available at Cranfield University. Alternatively, a set of prediction models are considered to take into account the effect of flexibility, wingtip deflection and flight conditions. Currently, these prediction models are based on wingtip deflection angle and angle-ofattack.

Further work regarding the identification of changes to aerodynamic derivatives includes the derivation of a larger aerodynamic database, extending the morphing dihedral to obtain local anhedral and extended flight envelope. The effect of hinge flare angle and mass can also be investigated for a more thorough understanding of the impact of such devices. Furthermore, directional and longitudinal motion should be investigated using conventional controls to capture the multi-directional aerodynamic derivative shifts. Results presented in this paper are used in further investigations ${ }^{17}$ focusing on pilot-in-the-loop simulations of morphing wingtips. 


\section{Acknowledgments}

This work is supported and developed in collaboration with Airbus Group, Innovate UK and the Aerospace Technology Institute (UK ATI). The authors would also like to acknowledge the support of the Indonesia Endowment Fund for Education (Lembaga Pengelola Dana Pendidikan - LPDP).

\section{References}

${ }^{1}$ ACARE Flightpath. 2050-Europe's Vision for Aviation. Advisory Council for Aeronautics Research in Europe, 2011.

${ }^{2}$ IEA. Transport, Energy and CO2: Moving towards Sustainability. Technical report, 2009.

${ }^{3}$ Lockheed martin official website. https://www.lockheedmartin.com/us/news/features/2014/5-unique-f35c-carriervariant-features.html, October 2014. Accessed on 1/12/2017.

${ }^{4}$ Marty K. Bradley and Christopher K. Droney. Subsonic Ultra Green Aircraft Research: Phase II. Technical report, 2012.

${ }^{5}$ David Hayes, Mudassir Lone, James Whidborne, and Etienne Coetzee. Evaluating the Rationale for Folding Wing Tips Comparing the Exergy and Breguet Approaches. In 55th AIAA Aerospace Sciences Meeting, 2017.

${ }^{6}$ David Allerton. Principles of flight simulation. Wiley, 2009.

${ }^{7}$ Robert K. Heffley and Wayne F. Jewell. Aircraft Handling Qualities Data. Technical report, 1972.

${ }^{8}$ A. Castrichini, V. Hodigere Siddaramaiah, D.E. Calderon, J.E. Cooper, T. Wilson, and Y. Lemmens. Preliminary investigation of use of flexible folding wing tips for static and dynamic loads alleviation. 4th Aircraft Structural Design Conference, October 2014.

${ }^{9}$ A. Castrichini, V. Hodigere Siddaramaiah, D.E. Calderon, J.E. Cooper, T. Wilson, and Y. Lemmens. Preliminary investigation of use of flexible folding wing tips for static and dynamic loads alleviation. Aeronautical Journal, November 2016.

${ }^{10}$ Stuart Andrews. Modelling and Simulation of Flexible Aircraft: Handling qualities and active load control. PhD thesis, 2011.

${ }^{11}$ Mudassir Lone and Alastair K. Cooke. Pilot-model-in-the-loop simulation environment to study large aircraft dynamics. Journal of Aerospace Engineering, 227(3):555-568, 2012.

${ }^{12}$ Mudassir Lone, Chi Kin Lai, Alastair Cooke, and James Whidborne. Framework for Flight Loads Analysis of TrajectoryBased Manoeuvres with Pilot Models. Journal of Aircraft, 51(2):637-650, 2014.

${ }^{13}$ Mudassir Lone. Pilot Modelling for airframe loads analysis. PhD thesis, 2013.

${ }^{14}$ Vilius Portapas, Alastair Cooke, and Mudassir Lone. Modelling framework for flight dynamics of flexible aircraft. Aviation, 20(4):173-182, 2016.

${ }^{15}$ Ravindra V. Jategaonkar. Flight Vehicle System Identification: A Time Domain Methodology. AIAA, Reston, USA, 2006.

${ }^{16}$ V.F. Klein and E.A. Morelli. Aircraft System Identification. Theory and Practice. AIAA Education Series, 2006.

${ }^{17}$ Gaetan Dussart, Sezsy Yusuf, Vilius Portapas, Guillermo Lopez, and Mudassir Lone. Method to assess lateral handling qualities of aircraft with wingtip morphing. In AIAA Aeroelasticity and Flight Dynamics Conference, AIAA SciTech Forum, Orlando, Florida, 8-12 January 2018. 
2018-01-13

\title{
Effect of wingtip morphing on the roll mode of a flexible aircraft
}

\author{
Dussart, Gaétan X.
}

AIAA

Dussart GX, Yusuf SY, Lone MM. (2018) Effect of wingtip morphing on the roll mode of a flexible aircraft. In: 2018 AIAA/ASCE/AHS/ASC Structures, Structural Dynamics, and Materials Conference, AIAA SciTech Forum, 8-12 January, Kissimmee, FL, USA. Paper number AIAA 2018-1683 http://dx.doi.org/10.2514/6.2018-1683

Downloaded from Cranfield Library Services E-Repository 